Article

\title{
New Coordinated Tuning of SVC and PSSs in Multimachine Power System Using Coyote Optimization Algorithm
}

\author{
Tawfik Guesmi $^{1,2, *}$, Badr M. Alshammari ${ }^{1} \oplus$, Yasser Almalaq ${ }^{1}$, Ayoob Alateeq ${ }^{1}$ and Khalid Alqunun ${ }^{1}$ \\ 1 Department of Electrical Engineering, University of Ha'il, Ha'il 2240, Saudi Arabia; \\ bms.alshammari@uoh.edu.sa (B.M.A.); ya.almalaq@uoh.edu.sa (Y.A.); a.alateeq@uoh.edu.sa (A.A.); \\ kh.alqunun@uoh.edu.sa (K.A.) \\ 2 Department of Electrical Engineering, National Engineering School of Sfax, University of Sfax, \\ Sfax 3038, Tunisia \\ * Correspondence: tawfik.guesmi@istmt.rnu.tn
}

Citation: Guesmi, T.; Alshammari, B.M.; Almalaq, Y.; Alateeq, A.; Alqunun, K. New Coordinated Tuning of SVC and PSSs in Multimachine Power System Using Coyote Optimization Algorithm. Sustainability 2021, 13, 3131. https:// doi.org/10.3390/su13063131

Academic Editor: Ayman Attya

Received: 15 February 2021

Accepted: 8 March 2021

Published: 12 March 2021

Publisher's Note: MDPI stays neutral with regard to jurisdictional claims in published maps and institutional affiliations.

Copyright: (c) 2021 by the authors. Licensee MDPI, Basel, Switzerland. This article is an open access article distributed under the terms and conditions of the Creative Commons Attribution (CC BY) license (https:// creativecommons.org/licenses/by/ $4.0 /)$.

\begin{abstract}
This paper presents a new approach for coordinated design of power system stabilizers (PSSs) and static VAR compensator (SVC)-based controller. For this purpose, the design problem is considered as an optimization problem whose decision variables are the controllers' parameters. Due to nonlinearities of large, interconnected power systems, methods capable of handling any nonlinearity of power networks are mostly preferable. In this regard, a nonlinear time domain based objective function is used. Then, the coyote optimization algorithm (COA) is employed for solving this optimization problem. In order to ensure the robustness and performance of the proposed controller (COA-PSS\&SVC), the objective function is evaluated for various extreme loading conditions and system configurations. To show the contribution of the coordinated controllers on the improvement of the system stability, PSSs and SVC are optimally designed in individual and coordinated manners. Moreover, the effectiveness of the COA-PSS\&SVC is assessed through comparison with other controllers. Nonlinear time domain simulation shows the superiority of the proposed controller and its ability in providing efficient damping of electromechanical oscillations.
\end{abstract}

Keywords: power system stabilizer; static VAR compensator; electromechanical oscillations; nonlinear time domain simulation; coyote optimization algorithm

\section{Introduction}

Industrialization and population growth are the primary factors for which the consumption of electric energy is steadily increasing. To have a balance between production and consumption, at first sight, it is necessary to increase the number of power stations, lines, transformers, etc., which implies an increase in cost and environmental degradation. Consequently, it is now important to have mesh networks and to work close to the stability limits in order to meet these new requirements. The latter oblige power companies and especially electric power transmission companies to operate around their limits of stability, due to the deregulation of modern power grids and the electricity market opening. This imposes an increase in the number of operating diagrams, and consequently the generation of multiple inter-area mode oscillations in the range of 0.17 to $0.4 \mathrm{~Hz}$ and local mode oscillations mostly around $1 \mathrm{~Hz}$ [1], which can lead to the failure of the network infrastructures. Indeed, this phenomenon is accompanied by a large oscillating power transit, which can lead to blackouts. In addition, these low frequency oscillations (LFOs) may cause system separation if they are not adequately damped. To face these adverse phenomena, power system stabilizers (PSSs) have long been used to improve power system stability and enhance system damping of inter-area and local oscillation modes. These stabilizers are employed to add damping torque to the generator rotor oscillations derived from speed, frequency or power of the generator where it is connected. Traditionally, PSS controllers are equipped with lead-lag compensators that are tuned independently by using linear 
approximations. However, power networks are nonlinear and complex that makes the use of nonlinear models instead of linear approximations more advisable to treat any nonlinearity in the tuning problem. Moreover, recent research works reveal that if only one PSS is tuned, the required damping level cannot be reached. Thus, it is advised to ensure coordination between the design processes of all PSSs [2]. From literature review such as in [3], it is shown that PSSs regulators may fail sometimes to provide adequate damping torque for inter-area modes.

In recent years, power electronic-based flexible AC transmission systems (FACTS) controllers have been considered as efficient alternative solutions. Generally, FACTS devices have been employed for handling different power system control problems [4]. The recent development of FACTS devices opens up new prospects for more intense exploitation of power networks by continuous and rapid action on the various network parameters such as phase shift, voltage and transmission line impedance. Thus, power flow will be better controlled and the voltages will be better maintained within their rated limits, which will make it possible to increase the stability margins and to tend towards the thermal limits of the lines. In addition, thanks to their rapid response time to changes in power networks, FACTS devices have emerged as effective tools for damping LFOs as an alternative or complement to PSSs. However, the combination of PSSs and FACTS devices in the same network has raised a new problem in terms of coordination between these regulators. Indeed, it is essential to ensure that there is a good coordination between these devices in a way that their actions are not negative in view of the security of the network.

One of the well-known shunt FACTS devices, named static VAR compensator (SVC), is considered as a competent device to provide adequate damping of the LFOs in modern power systems after apparition of disturbances. It also has the capability of regulation of bus voltage at its terminals by injecting controllable reactive power into the power network through the bus where it is connected. In last few years, many research studies have proposed design techniques for SVC devices to enhance power system stability. The most of these researches have been focused on the coordinated design of SVC and PSS controllers. A comprehensive study of the PSS and SVC controllers when applied through coordinated manner and also separately has been investigated in [5,6]. A robust method based on the bacteria foraging optimization algorithm (BFOA) has been presented in [6] for the optimum design of SVC controller. However, only SVC device has been examined and contribution of PSSs is not investigated. Esmaili et al. [7] proposed a hybrid method combining particle swarm optimization (PSO) and bacterial foraging algorithm (BFA) for the optimal coordination of PSSs and SVC equipped with power oscillation damping (POD) controllers. The coordinated design between PSSs and POD-based SVC to damp out LFOs has been also investigated in [8] where the POD controller has been based on the modern multi-band PSS. The optimum tuning of three SVCs controllers for mitigating fault-induced delayed voltage recovery (FIDVR) and enhancement of angular stability has been illustrated in [9]. The optimal tuning of PSSs and FACTS devices for power system stability enhancement has been also addressed in [10-13]. In [11], the optimal combination of thyristor-controlled series capacitor (TCSC), SVC and PSSs has been investigated for the suppression of LFOs where the parameters of controllers are optimized based on eigenvalue analysis. Dey et al. [12] have studied the contribution of SVC and TCSC on the small signal stability of a power network incorporating wind farm, where eigenvalue analysis and time domain simulation (TDS) have been conducted for various disturbance scenarios. A comprehensive study of the impacts of PSS and unified power flow controller (UPFC) for the enhancement of power system stability has been presented in [13]. In other works, the optimal allocation of FACTS devices along with the optimal coordination between these devices and PSSs regulators has been investigated [14,15]. For example, Ref. [14] has proven that suitable SVC location in power systems may affect positively the system stability and loadability and, on the other hand, decrease the system losses, under contingencies. Baadji et al. [15] has illustrated the importance of the SVC location on system voltages under line outages. 
Recently, other optimization methods have been suggested for handling system stability enhancement via optimal tuning of PSSs and FACTS devices. For instance, flower pollination algorithm (FPA) has been employed in [16] for the optimal tuning of SVC device where the speed deviations of all machines are used as performance index. In [17], a combination of gravitational search algorithm (GSA) and gradient local search method has been presented for robust tuning of PSSs under various loads. The goal has been to maximize the damping ratio of the dominant electromechanical mode. In the last two decades, PSO-based techniques have been attracted much attention for solving various problems in power system field [18]. For instance, Ambafi and Adamu [19] have used a multi-objective PSO algorithm for the optimum coordination between PSSs regulators and FACTS devices in order to optimally damp out inter-area oscillations. The authors have emerged in the objective function four metrics describing the voltage deviation, total real losses and percentage compensation of FACTS devices. However, dynamic performance of the controllers has not been considered. In other works, firefly algorithm (FA) [20], which is a biologically inspired optimization algorithm, has been also applied for power system stability enhancement [21]. An optimal tuning of PSSs and FACTS controllers, using stochastic population-based sine-cosine algorithm (SCA), is proposed in [22].

In the context that new optimization algorithms are constantly welcome, a new population-based optimization technique, called coyote optimization algorithm (COA), has been recently developed by Pierezan and Coelho by [23]. COA-based optimization method emulates the social behavior and adaptation of coyote, which are canis latrans species native to North America. In contrast to grey wolf optimizer (GWO), the social structure and the transfer of the experience between these animals constitute the basic principle for balancing exploitation and exploration abilities. The performance of the COA is assessed in the aforementioned reference through comparison with other meta-heuristic techniques over various benchmark functions.

Within this context, a new approach based on the COA technique is described in this paper to improve the power system stability by ensuring an optimal damping of the LFOs. To achieve this goal, an optimal coordination of PSSs and SVC controllers is provided. This ensures satisfactory damping of rotor oscillations and guarantees the stability of the system. The design problem is described by an optimization problem where the parameters of all controllers are considered as decision variables. The optimum tuning of the controller parameters is achieved by minimizing a time domain-based objective function called integral of time multiplied absolute value of the error (ITAE) over different loading conditions. An optimization method based on the COA technique is adopted for the minimization of the objective function. To the best of our knowledge, the proposed method has not been applied before for the coordinated tuning of PSS and SVC controllers. For validation of the proposed controllers, three metrics describing the system response are investigated. Values of these metrics, which are ITAE, settling times and figure of demerit (FD), are compared with those of other controllers.

The rest of this paper is organized as follows: Section 2 develops the model of a power network and its dynamic behavior. Section 3 presents the structure of the SVC controller. The formulation of the problem as an optimization problem is presented in Section 4 . Section 5 contains the presentation of the proposed optimization technique and its implementation for the tuning of the controllers. Discussion of simulation results is presented in Section 6. Finally, the study's conclusions and future work are summarized in Section 7.

\section{Power Network Modeling}

Generally, the behavior of a power system may be described by the following nonlinear system $[24,25]$.

$$
\begin{gathered}
\dot{X}=f(X, Y, U) \\
0=g(X, Y)
\end{gathered}
$$




$$
W=h(X, Y, U)
$$

where, $X=\left[\begin{array}{llll}\delta & \omega & E_{q}^{\prime} & E_{f d}\end{array}\right]^{T}$ is the vector of state variables, $Y$ is the vector of the algebraic variables including phase angles and magnitudes of bus voltages, $W$ is a set of output variables and $U$ is the input vector including the outputs of all controllers. $f$ is a set of the first order nonlinear differential equations that represent system and controller dynamics and $g$ is a set of non-linear algebraic equations that describe the network power flow equations. $h$ is a set of equations that represent output variables. $\delta$ and $\omega$ are rotor angle and speed deviation, respectively. $E_{q}^{\prime}$ and $E_{f d}$ are internal and field voltages, respectively.

In this study, the conventional lead-lag PSS [26] is adopted. As shown in Figure 1, the proposed PSS consists of a gain $K_{i}$, a washout bloc with time constant $T_{W}$ and two lead-lag blocks. The gain $K_{i}$ corresponds to the value of the damping introduced by the PSS to mitigate LFOs. Theoretically, its value must satisfy the damping of the dominant modes of the system without running the risk of degrading the stability of the other modes or the transient stability. The washout bloc eliminates the LFOs presented in the input signal. It also removes the DC component of the input signal speed. Therefore, the PSS only reacts when there are variations in speed. The time constant of this filter must be large enough to allow the signals whose frequency is located in the desired band, to be transmitted without attenuation. However, it should not be too large to avoid leading to undesirable generator voltage variations. Generally, $T_{W}$ ranges from 1 to $20 \mathrm{~s}$. A remarkable improvement on the stability of the first oscillation is obtained with a value fixed at $10 \mathrm{~s}$ [27]. To better ensure the stability of the system, a lead-lag block is mostly employed for phase compensation. Generally, two or more first-order blocks for phase compensation are mostly employed where the time constants $T_{1}$ and $T_{3}$ for phase-lead compensation and $T_{2}$ and $T_{4}$ for phaselag compensation are adjustable. These time constants vary from 0.01 to $1.5 \mathrm{~s} \mathrm{[28].} \mathrm{In}$ Figure $1, K_{A}$ and $T_{A}$ are the amplifier gain and the amplifier time constants of the excitation system, respectively. $V_{r e f}$ and $V_{t}$ are reference and generator terminal voltages, respectively.

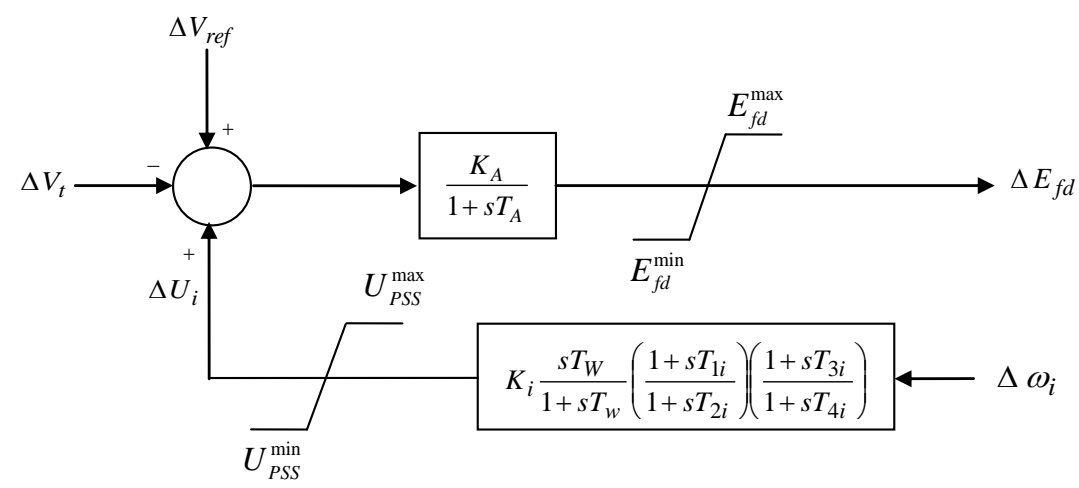

Figure 1. Lead-lag power system stabilizer (PSS) with excitation system.

The choice of the PSS input signal represents a critical step in the design of the PSS. However, the sensitivity of the input signal to electromechanical oscillations constitutes the main parameter in this choice. In other words, the oscillation modes must be observable in the chosen signal. From literature review, it is found that a good result can be obtained if the PSS input is the rotor speed deviation $(\Delta \omega)$, the variation of the output power of the machine $(\Delta P e)$ or the frequency at the busbar. Since the PSS is used to produce an electrical torque proportional to the speed variation, it therefore appears more suitable to use the speed deviation as PSS input.

\section{Structure of the SVC-Based Stabilizer}

The SVC device used in this study is connected to the AC system via a set up transformer to maintain the network voltage constantly at a specified value by varying its effective reactance. As seen in Figure 2, the system is a thyristor-control reactor/fixed 
capacitor (TCR/FC). The firing angle of the thyristors controls the value of the effective reactance $X_{e}$ of the SVC, as written in the following equation [13].

$$
X_{e}=X_{c} \frac{\pi / r_{x}}{\sin 2 \alpha-2 \alpha+\pi\left(2-1 / r_{x}\right)}
$$

where, $\pi / 2 \leq \alpha \leq \pi$ and $r_{x}=\frac{X_{e}}{X_{L}}$.

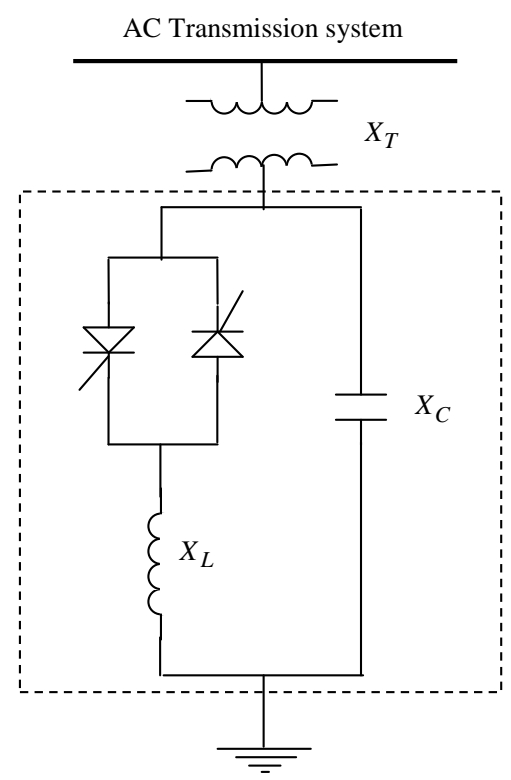

Figure 2. Static VAR compensator (SVC) equivalent circuit.

Figure 3 illustrates the structure of the SVC controller. It consists of a thyristors firing control system and a POD controller similar to the PSS structure. The input signal of the POD controller can be chosen from the normalized speed deviations of machines. Therefore, the dynamic equation of the effective susceptance of the SVC can be expressed by the following equation.

$$
\dot{B}_{e}=\frac{1}{T_{r}}\left[-B_{e}+K_{r}\left(V_{r e f}-V_{t}+V_{s}\right)\right]
$$

where, $K_{r}$ and $T_{r}$ are the gain and time constant of the thyristors firing control system, respectively.

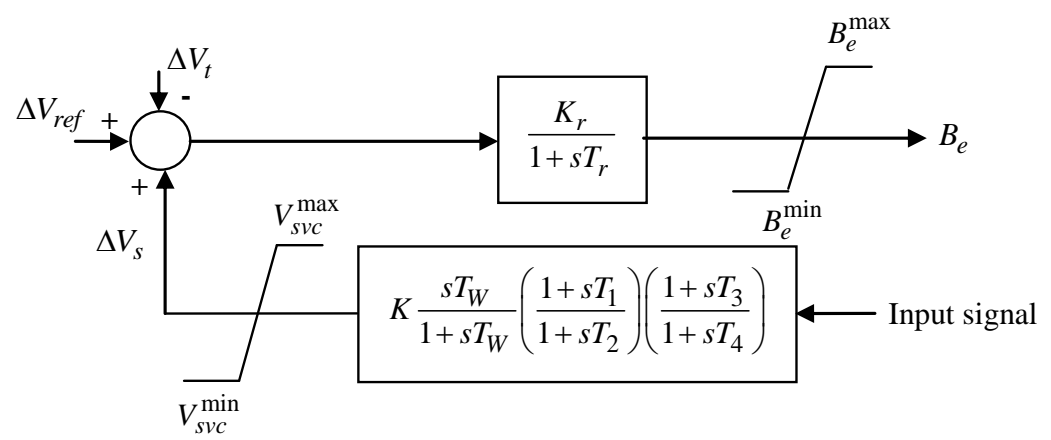

Figure 3. Block diagram of SVC.

\section{Damping Controller Design}

In dynamic conditions, PSS and FACTS devices are generally used to damp out power system oscillations. Furthermore, nonlinear analysis of system stability is often suggested 
to tune their parameters. In this study, a nonlinear time domain simulation (NTDS)-based objective function called ITAE is used for the optimal setting of PSSs and SVC controllers. ITAE based on the system performance characteristics can be defined by Equation (6). It is worth mentioning that the minimum value of that index corresponds to a good damping of the system.

$$
\text { ITAE }=\frac{1000 \sum_{i=1}^{N} \int_{0}^{t_{\text {sim }}} t\left(\left|\Delta \omega_{i}\right|\right) d t}{N}
$$

where, $N$ is the number of machines.

For various loading conditions, the objective function can be described by the following expression.

$$
J=\max \left\{I T A E_{i}, i \in \text { set of loading conditions }\right\}
$$

Therefore, the design problem aims to minimize $J$ by respecting the adjustable parameter bounds given by Equations (8)-(12).

$$
\begin{aligned}
& K_{i}^{\min } \leq K_{i} \leq K_{i}^{\max } \\
& T_{1 i}^{\min } \leq T_{1 i} \leq T_{1 i}^{\max } \\
& T_{2 i}^{\min } \leq T_{2 i} \leq T_{2 i}^{\max } \\
& T_{3 i}^{\min } \leq T_{3 i} \leq T_{3 i}^{\max } \\
& T_{4 i}^{\min } \leq T_{4 i} \leq T_{4 i}^{\max }
\end{aligned}
$$

For both controllers PSS and SVC, the washout time constant $T_{W i}$ is fixed to $10 \mathrm{~s}$. Typical ranges of the decision variables are [1-20] for $K_{i}$ and [0.01-1.5] for $T_{1 i}$ to $T_{4 i}$.

\section{Implementation of the COA for Optimal Tuning of Controllers}

\subsection{Coyote Optimization Algorithm}

Coyote optimization algorithm (COA) is a nature-inspired optimization technique proposed recently by Pierezan and Coelho [23]. Unlike grey wolf optimizer (GWO), the social structure and the transfer of the experience between individuals constitute the basic principle of the COA without considering the dominance rules. In COA, the population of coyote is subdivided into $N_{p}$ packs of coyotes with the same size $N_{c}$. Therefore, the population size is $N_{p} \times N_{c}$. Generally, pack members are sociable with each other. The social conditions (soc) of the $c$-th individual in the $p$-th pack and at the $t$-th iteration is described by a candidate solution as given in the following equation.

$$
\operatorname{soc}_{c}^{p, t}=\left(x_{1}, x_{2}, \ldots, x_{D}\right)
$$

where, $D$ is the dimension of the search space and $x_{i} \in\left\{x_{1}, x_{2}, \ldots, x_{D}\right\}$ is the $i$-th decision variable.

The fitness function that describes the adaptation of the $c$-th individual to its social conditions is given as follows. In Equation (14), function $f: \Re^{D} \rightarrow \Re$ represents the function to be optimized.

$$
\operatorname{fit}_{c}^{p, t}=f\left(\operatorname{soc}_{c}^{p, t}\right)
$$

As presented in $[28,29]$, some coyotes may leave their packs to other packs or to become solitary coyotes. This mechanism reinforces the interaction between population members in order to enhance the diversification of the population.

In COA, the coyote that dominated the territory and reproduced is defined as an alpha. For a minimization problem, the alpha of the $p$-th pack at the $t$-th iteration is the candidate solution defined as follows.

$$
\alpha^{p, t}=\left\{\operatorname{soc}_{c}^{p, t} \mid \arg _{c}=\left\{1,2, \ldots, N_{c}\right\} \min f\left(\operatorname{soc}_{c}^{p, t}\right)\right\}
$$


In the COA algorithm, all coyotes' information are described as cultural tendency, as illustrated in the following equation.

$$
\text { cult }_{j}^{p, t}= \begin{cases}O_{A, j}^{p, t}, & \text { if } N_{c} \text { is odd } \\ \frac{O_{B, j}^{p, t}+O_{B+1, j}^{p, t},}{2}, & \text { otherwise }\end{cases}
$$

where, $A=\frac{N_{c}+1}{2}, B=\frac{N_{c}}{2}$ and $O^{p, t}$ is the ranked social conditions of all coyotes in the $p$-th pack at the $t$-th iteration.

Along with eviction mechanism, birth and death events are incorporated in the COA in order to enhance the packs' diversification. Indeed, two parents are selected randomly to produce coyote pups as illustrated in Equation (17). Pups' rates of survival are evidently linked to the social conditions of parents. The disappearance of each pup or coyote $c$ is linked to its age $\left(a g e_{c}^{p, t}\right)$.

$$
\operatorname{pup}_{j}^{p, t} \begin{cases}\operatorname{soc}_{r_{1, j}, j}^{p, t}, & r n d_{j}<P_{s} \text { or } j=j_{1} \\ \operatorname{soc}_{r_{2, j},}^{p}, & \text { rnd } d_{j} \geq P_{s}+P_{a} \text { or } j=j_{2} \\ R_{j}, & \text { otherwise }\end{cases}
$$

where $\operatorname{soc}_{r_{1}, j}^{p, t}$ and $s o c_{r_{2}, j}^{p, t}$ are the $j$-th decision variable of two social conditions $\operatorname{soc} c_{r_{1}}^{p, t}$ and $s o c_{r_{2}}^{p, t}$ randomly selected from the $p$-th pack at $t$-th iteration. $j_{1}$ and $j_{2}$ are two integer numbers selected randomly from $\{1,2, \ldots, D\} . R_{j}$ is a random number selected randomly from the interval $\left[X_{j}^{\min }, X_{j}^{\max }\right] . P_{s}$ and $P_{a}$ are scatter probability and association probability, respectively.

In order to guarantee the balance between birth and death, a set of birth and death rules is incorporated in the COA. Detailed mathematical representation of COA can be found in [23].

\subsection{COA for Optimal Controllers' Design}

In this study, the optimal tuning of PSS and SVC controllers is formulated as a minimization problem. The objective function of the problem is illustrated in Equation (7) whilst the problem decision variables are the controllers' parameters. Problem constraints that describe the lower and upper bounds of the decision variables are illustrated in Equations (8)-(12). These bounds are used in Equation (14) to generate the initial population of coyotes. In order to solve the studied problem, the COA-based coordinated design of PSSs and SVC is implemented as given in Figure 4. 


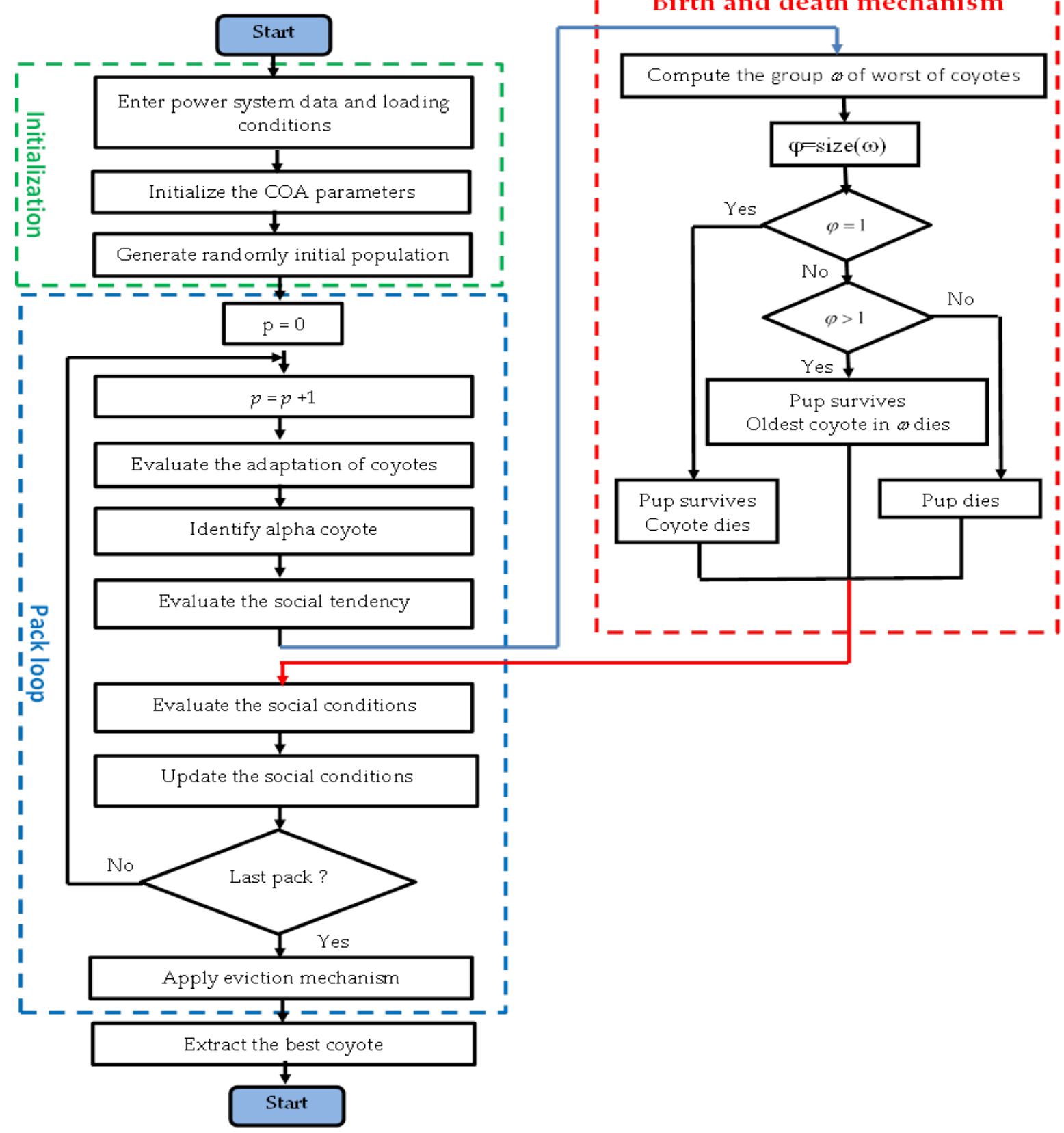

Figure 4. Flowchart of coyote optimization algorithm (COA)-based optimization method.

\section{Simulation Results}

\subsection{Statistical Results of the COA Algorithm}

In this sub-section, the proposed technique is assessed using eight unimodal and multimodal benchmark functions. These functions are frequently used to test the exploitation and exploration capabilities of the optimization algorithms. Table 1 shows the test functions and their proprieties. The global minima of these benchmark functions are zero. 
Table 1. Characteristics of used benchmark functions.

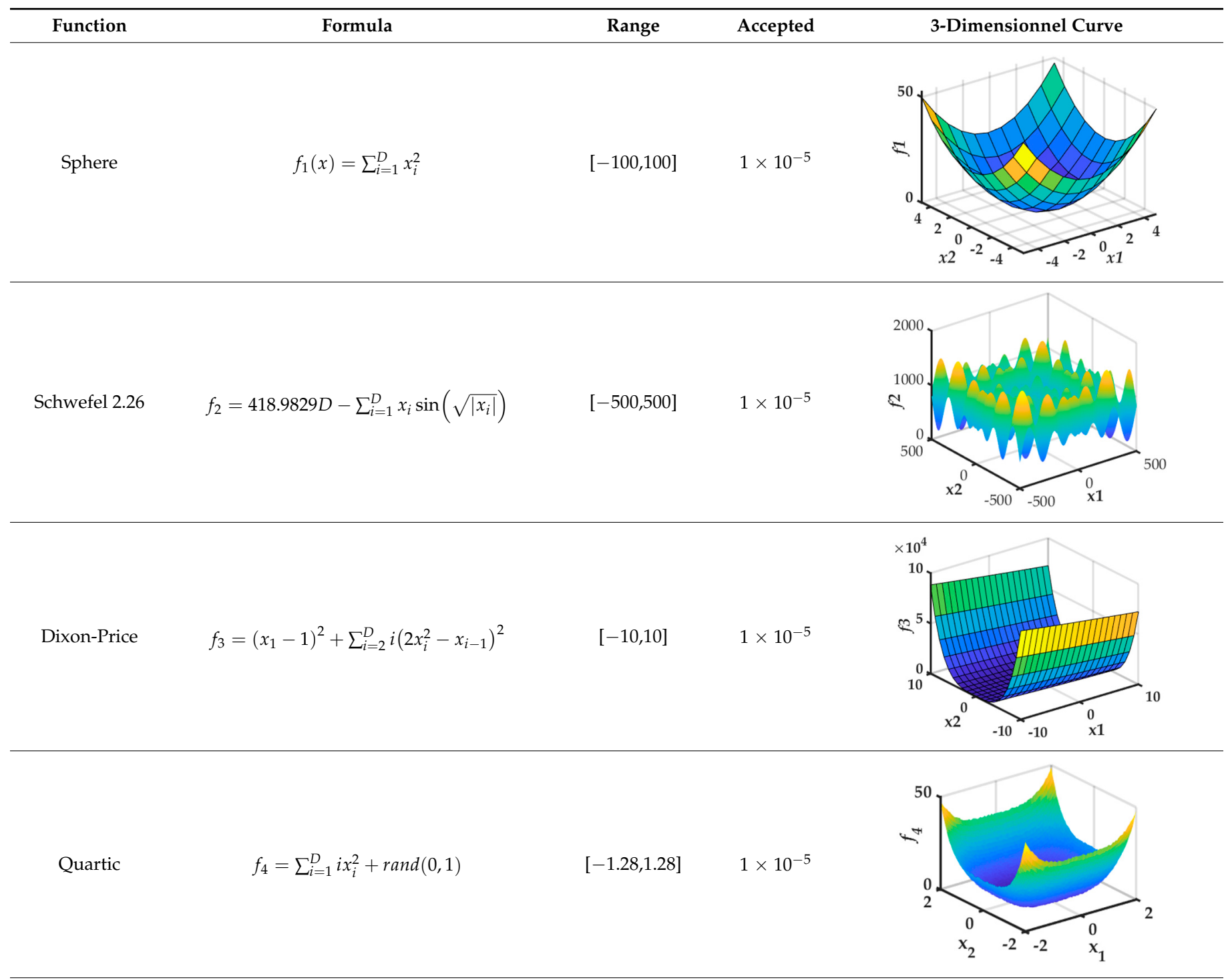

Griewank $\quad f_{5}(x)=\sum_{i=1}^{D} \frac{x_{i}^{2}}{4000}-\prod_{i=1}^{D} \cos \left(\frac{x_{i}}{\sqrt{i}}\right)+1 \quad[-600,600] \quad 1 \times 10^{-5}$

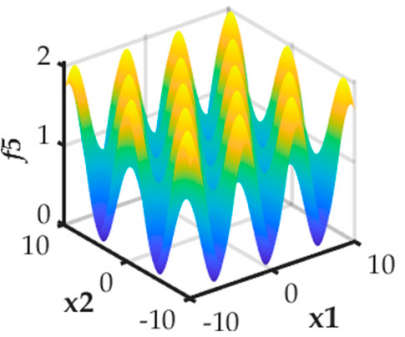

Rastrigin

$$
f_{6}(x)=\sum_{i=1}^{D}\left(x_{i}^{2}-10 \cos \left(2 \pi x_{i}+10\right)\right)
$$$$
[-5.12,5.12]
$$$$
1 \times 10^{-2}
$$

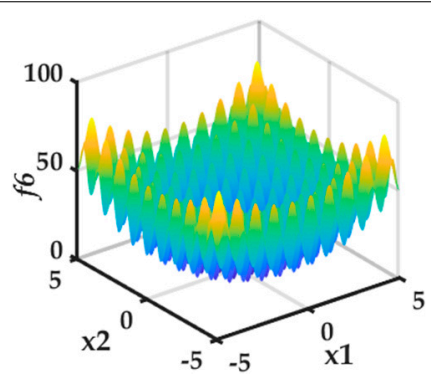


Table 1. Cont.

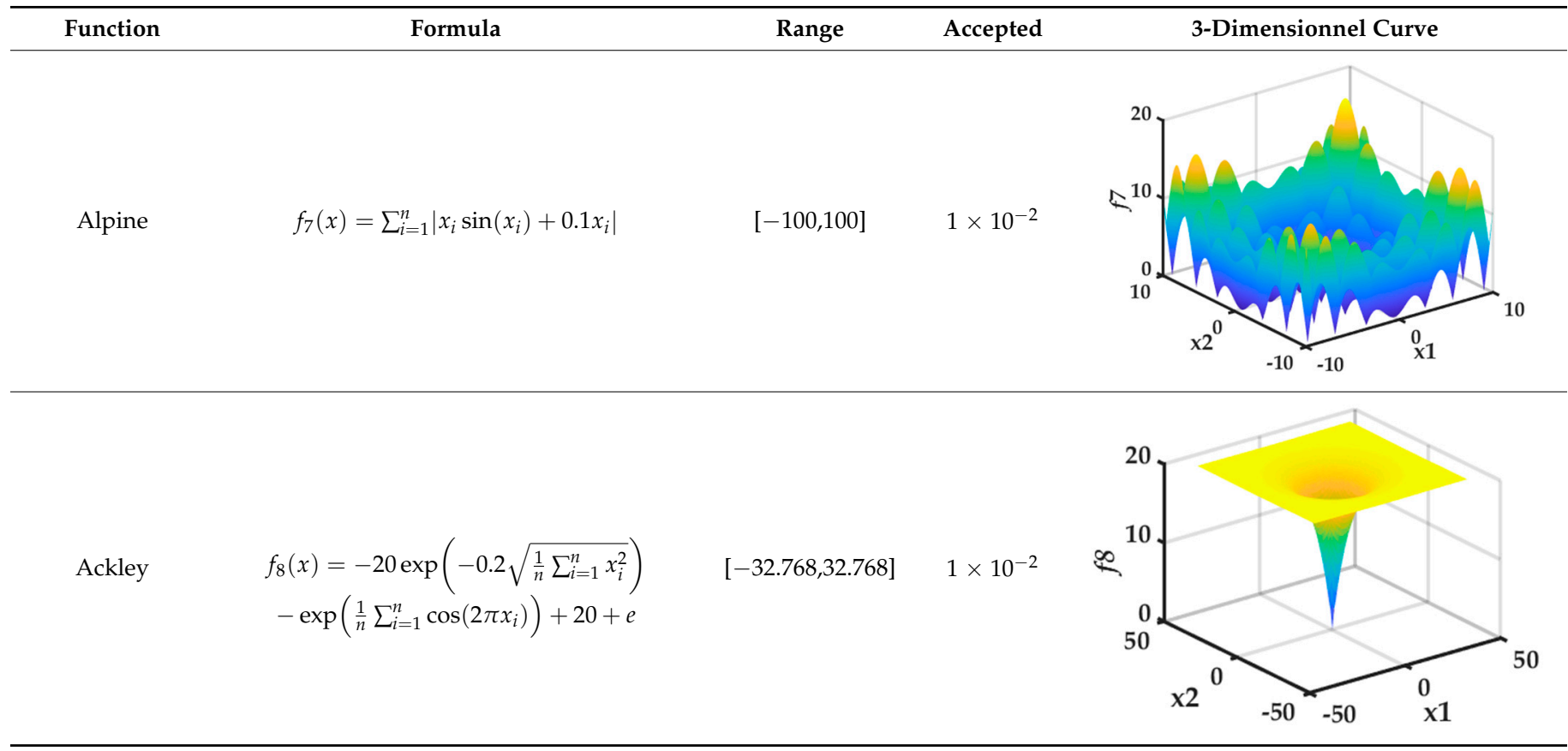

Statistical results, obtained using COA technique, are compared with those achieved by COA, PSO, genetic algorithm (GA), artificial bee colony (ABC), invasive weed optimization algorithm (IWO) and FA. All test problems are 30-dimensional input and onedimensional output. For fair comparison, optimum results for all benchmark functions are obtained after 30 independent runs. Table 2 shows the statistical results including best, mean and standard deviation values. From Table 2, it can be seen that COA achieves the best results compared to the other techniques.

Table 2. Statistical results for 30-dimensional test functions.

\begin{tabular}{|c|c|c|c|c|c|c|c|}
\hline Function & & $\mathrm{COA}$ & PSO & GA & $\mathrm{ABC}$ & IWO & FA \\
\hline \multirow{3}{*}{$f_{1}$} & Best & $3.49 \times 10^{-11}$ & $1.69 \times 10^{-8}$ & $8.51 \times 10^{-3}$ & $1.01 \times 10^{-5}$ & $3.10 \times 10^{-5}$ & $4.64 \times 10^{-8}$ \\
\hline & Mean & $9.84 \times 10^{-11}$ & $5.17 \times 10^{-8}$ & $9.75 \times 10^{-3}$ & $3.25 \times 10^{-5}$ & $7.49 \times 10^{-5}$ & $5.19 \times 10^{-8}$ \\
\hline & Std & $3.66 \times 10^{-11}$ & $3.02 \times 10^{-8}$ & $8.67 \times 10^{-4}$ & $2.79 \times 10^{-5}$ & $3.86 \times 10^{-5}$ & $4.06 \times 10^{-9}$ \\
\hline \multirow{3}{*}{$f_{2}$} & Best & $4.86 \times 10^{-9}$ & $3.12 \times 10^{-8}$ & $9.92 \times 10^{-4}$ & $7.23 \times 10^{-6}$ & $1.50 \times 10^{-2}$ & $1.46 \times 10^{-8}$ \\
\hline & Mean & $7.03 \times 10^{-9}$ & $9.48 \times 10^{-8}$ & $1.25 \times 10^{-3}$ & $8.87 \times 10^{-5}$ & $1.87 \times 10^{-2}$ & $2.17 \times 10^{-8}$ \\
\hline & Std & $3.14 \times 10^{-9}$ & $8.69 \times 10^{-8}$ & $1.74 \times 10^{-4}$ & $7.40 \times 10^{-5}$ & $2.11 \times 10^{-3}$ & $6.52 \times 10^{-9}$ \\
\hline \multirow{3}{*}{$f_{3}$} & Best & $6.67 \times 10^{-9}$ & $6.96 \times 10^{-6}$ & $4.18 \times 10^{-1}$ & $7.62 \times 10^{-5}$ & $1.68 \times 10^{-3}$ & $6.75 \times 10^{-6}$ \\
\hline & Mean & $6.69 \times 10^{-6}$ & $1.13 \times 10^{-5}$ & $6.56 \times 10^{-1}$ & $1.37 \times 10^{-3}$ & $4.96 \times 10^{-3}$ & $7.36 \times 10^{-6}$ \\
\hline & Std & $3.87 \times 10^{-8}$ & $6.79 \times 10^{-6}$ & $1.62 \times 10^{-1}$ & $2.84 \times 10^{-3}$ & $3.06 \times 10^{-3}$ & $1.00 \times 10^{-6}$ \\
\hline \multirow{3}{*}{$f_{4}$} & Best & $3.93 \times 10^{-8}$ & $4.57 \times 10^{-7}$ & $3.20 \times 10^{-5}$ & $3.36 \times 10^{-6}$ & $4.57 \times 10^{-7}$ & $4.74 \times 10^{-8}$ \\
\hline & Mean & $6.27 \times 10^{-8}$ & $8.11 \times 10^{-7}$ & $6.36 \times 10^{-5}$ & $6.74 \times 10^{-6}$ & $8.11 \times 10^{-7}$ & $9.47 \times 10^{-8}$ \\
\hline & Std & $1.62 \times 10^{-8}$ & $2.29 \times 10^{-7}$ & $1.43 \times 10^{-5}$ & $2.14 \times 10^{-6}$ & $2.29 \times 10^{-7}$ & $3.75 \times 10^{-8}$ \\
\hline \multirow{3}{*}{$f_{5}$} & Best & $1.71 \times 10^{-10}$ & $6.03 \times 10^{-7}$ & $9.97 \times 10^{-3}$ & $4.29 \times 10^{-4}$ & $1.01 \times 10^{-4}$ & $1.92 \times 10^{-7}$ \\
\hline & Mean & $4.54 \times 10^{-10}$ & $1.94 \times 10^{-5}$ & $1.01 \times 10^{-2}$ & $5.19 \times 10^{-4}$ & $2.12 \times 10^{-4}$ & $2.38 \times 10^{-7}$ \\
\hline & Std & $1.67 \times 10^{-10}$ & $3.68 \times 10^{-5}$ & $1.03 \times 10^{-4}$ & $6.67 \times 10^{-5}$ & $8.26 \times 10^{-5}$ & $3.51 \times 10^{-8}$ \\
\hline \multirow{3}{*}{$f_{6}$} & Best & $1.71 \times 10^{-8}$ & $2.00 \times 10^{-4}$ & $2.64 \times 10^{-3}$ & $5.14 \times 10^{-4}$ & $6.07 \times 10^{-4}$ & $1.60 \times 10^{-4}$ \\
\hline & Mean & $6.04 \times 10^{-6}$ & $3.04 \times 10^{-4}$ & $2.77 \times 10^{-3}$ & $7.13 \times 10^{-4}$ & $7.28 \times 10^{-4}$ & $2.98 \times 10^{-4}$ \\
\hline & Std & $8.40 \times 10^{-6}$ & $7.73 \times 10^{-5}$ & $1.01 \times 10^{-4}$ & $9.25 \times 10^{-5}$ & $1.08 \times 10^{-4}$ & $1.16 \times 10^{-4}$ \\
\hline
\end{tabular}


Table 2. Cont.

\begin{tabular}{cccccccc}
\hline Function & & COA & PSO & GA & ABC & IWO & FA \\
\hline \multirow{3}{*}{$f_{7}$} & Best & $6.30 \times 10^{-8}$ & $2.22 \times 10^{-7}$ & $3.28 \times 10^{-3}$ & $2.32 \times 10^{-5}$ & $1.88 \times 10^{-5}$ & $2.84 \times 10^{-7}$ \\
\cline { 2 - 8 } & Mean & $1.26 \times 10^{-7}$ & $2.97 \times 10^{-7}$ & $3.42 \times 10^{-3}$ & $4.10 \times 10^{-5}$ & $2.63 \times 10^{-5}$ & $3.16 \times 10^{-7}$ \\
\cline { 2 - 8 } & Std & $4.46 \times 10^{-8}$ & $7.05 \times 10^{-8}$ & $1.22 \times 10^{-4}$ & $1.06 \times 10^{-5}$ & $5.87 \times 10^{-6}$ & $1.58 \times 10^{-8}$ \\
\hline \multirow{3}{*}{$f_{8}$} & Best & $7.37 \times 10^{-8}$ & $2.54 \times 10^{-7}$ & $7.45 \times 10^{-5}$ & $3.24 \times 10^{-5}$ & $2.81 \times 10^{-5}$ & $4.07 \times 10^{-7}$ \\
\cline { 2 - 7 } & Mean & $2.01 \times 10^{-7}$ & $3.89 \times 10^{-7}$ & $7.95 \times 10^{-5}$ & $4.09 \times 10^{-5}$ & $3.88 \times 10^{-5}$ & $5.37 \times 10^{-7}$ \\
\cline { 2 - 7 } & Std & $7.24 \times 10^{-8}$ & $8.37 \times 10^{-8}$ & $3.12 \times 10^{-6}$ & $3.26 \times 10^{-6}$ & $6.31 \times 10^{-6}$ & $5.84 \times 10^{-6}$ \\
\hline
\end{tabular}

COA, coyote optimization algorithm; PSO, particle swarm optimization; GA, genetic algorthm; ABC, artificial bee colony; IWO, invasive weed optimization; FA, firefly algorithm.

\subsection{Test Cases and Discussions}

To assess the effectiveness and robustness of the proposed COA-based controllers in the improvement of the power system stability, the 3-machine 9-bus WSCC (western system coordinating council) is considered in this paper. The single line diagram of the test system is given in Figure 5. The system data in detail are given in [29]. In this study, it is assumed that all generators except G1 are equipped with PSS. In order to determine the best location of SVCs devices, different strategies have been illustrated in the literature $[6,19]$. In [6], two strategies based on studying the impact of load percentage and line outage on load bus voltages have been applied on the WSCC system. As given in [6], bus number 5 is selected as the best placement for the SVC device in this paper.

To assess the performance of the proposed controllers, four different loading conditions are considered. These system operating conditions are shown in Table 3.

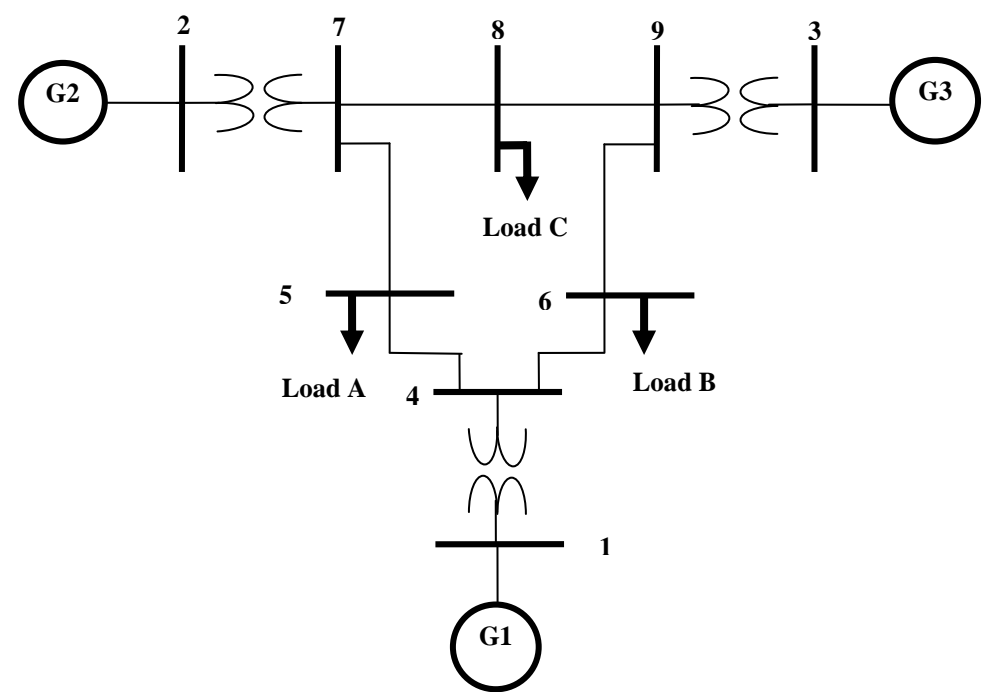

Figure 5. Single line diagram for 3-machine 9-bus power system.

Table 3. System operating conditions (in pu).

\begin{tabular}{cccccccccc}
\hline & & \multicolumn{2}{c}{ Base Case } & \multicolumn{2}{c}{ Case 1 } & \multicolumn{2}{c}{ Case 2 } & \multicolumn{2}{c}{ Case 3 } \\
\cline { 2 - 10 } & & $\boldsymbol{P}$ & $\boldsymbol{Q}$ & $\boldsymbol{P}$ & $\boldsymbol{Q}$ & $\boldsymbol{P}$ & $\boldsymbol{Q}$ & $\boldsymbol{P}$ & $\boldsymbol{Q}$ \\
\hline \multirow{3}{*}{ Gen } & G1 & 1.7164 & 0.6179 & 3.7556 & 1.8115 & 0.9614 & 0.1651 & 1.4721 & 1.0542 \\
\cline { 2 - 10 } & G2 & 1.6300 & 0.0662 & 1.9200 & 0.8755 & 0.800 & -0.0595 & 2.0000 & 0.5918 \\
\cline { 2 - 10 } & $\mathrm{G} 3$ & 0.8500 & -0.1071 & 1.2800 & 1.1939 & 0.4500 & 0.0035 & 1.5000 & 0.7055 \\
\hline \multirow{3}{*}{ Load } & $\mathrm{A}$ & 1.2500 & 0.5000 & 2.0000 & 0.8000 & 0.6500 & 0.5500 & 1.5000 & 0.9000 \\
\cline { 2 - 10 } & $\mathrm{B}$ & 0.9000 & 0.3000 & 1.8000 & 0.6000 & 0.4500 & 0.3500 & 1.2000 & 0.8000 \\
\cline { 2 - 10 } & $\mathrm{C}$ & 1.0000 & 0.3500 & 1.5000 & 0.6000 & 0.5000 & 0.2500 & 1.0000 & 0.5000 \\
\hline \multicolumn{2}{c}{ Local load at G1 } & 1.0000 & 0.3500 & 1.5000 & 0.7000 & 0.6000 & 0.2000 & 1.2000 & 0.4000 \\
\hline
\end{tabular}


In order to find the optimum values of controllers' parameters, the objective function given in Equation (7) is minimized considering two scenarios of severe fault disturbances under the loading conditions described above. In the first scenario, a 6-cycle fault disturbance is occurred in the line 5-7 close bus 5 . The fault is cleared by tripping the line 5-7 with successful reclosure after $1.0 \mathrm{~s}$. Scenario 2 is equivalent to scenario 1 with 0.2 per unit (pu) step increase in mechanical power. The fault is cleared by tripping the line 5-7 with successful reclosure after $1.0 \mathrm{~s}$. Results obtained by using the proposed optimization method COA are compared with those obtained using genetic algorithm (GA) and PSO techniques to investigate the COA performance. For fair comparison, these algorithms were run with the same population size (80) and maximum number of iterations (100). The best results are obtained after 30 independent runs of the optimization techniques. Statistical results with $95 \%$ confidence interval for COA, PSO and GA are tabulated in Table 4. As it can be seen, the proposed algorithm reached the best results in terms of mean value of best cost and standard deviation. The convergence characteristics of these algorithms, when they are applied for the optimum setting of PSS and SVC controllers, are illustrated in Figure 6.

Table 4. Statistical results with 95\% confidence factor.

\begin{tabular}{ccc}
\hline COA & PSO & GA \\
\hline $9.05 \times 10^{1} \pm 3.65 \times 10^{-5}$ & $3.85 \times 10^{1} \pm 4.25 \times 10^{1}$ & $4.01 \times 10^{1} \pm 4.50 \times 10^{1}$ \\
\hline
\end{tabular}

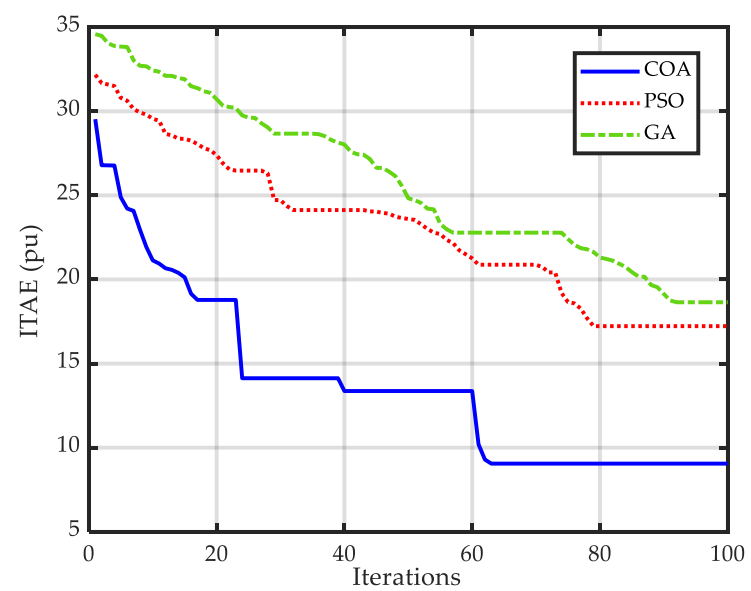

Figure 6. Convergence characteristics of COA, PSO and GA.

Optimum parameters of the controllers obtained using the nonlinear time domain based objective function are given in Table 5 . These results are obtained after the convergence of the proposed COA technique. To demonstrate the robustness of the coordination between PSSs and SVC controllers, an individual design is also carried out.

Table 5. Optimal setting parameters using COA.

\begin{tabular}{ccccccc}
\hline & \multicolumn{3}{c}{ Coordinated Design } & \multicolumn{3}{c}{ Individual Design } \\
\hline & PSS1 & PSS2 & SVC & PSS1 & PSS2 & SVC \\
\hline$K$ & 20.6237 & 17.4638 & 28.9023 & 16.1185 & 5.8064 & 98.2455 \\
\hline$T_{1}$ & 0.3239 & 0.1893 & 0.1232 & 0.3480 & 0.1744 & 0.2280 \\
\hline$T_{2}$ & 0.0282 & 0.0976 & 0.0574 & 0.0132 & 0.0811 & 0.0179 \\
\hline$T_{3}$ & 0.1095 & 0.6131 & 0.0709 & 0.0733 & 0.5726 & 0.3355 \\
\hline$T_{4}$ & 0.0282 & 0.0493 & 0.0113 & 0.0578 & 0.0257 & 0.0322 \\
\hline
\end{tabular}


In order to show the contribution of the coordinated design compared to the uncoordinated design variations of the angular speeds, $\omega_{12}$ and $\omega_{13}$ for various loading conditions and under the fault scenarios 1 and 2 are shown in Figure 7. Note that $\omega_{12}=\omega_{2}-\omega_{1}$ and $\omega_{13}=\omega_{3}-\omega_{1}$. Figure 8 shows clearly that POD-based SVC controller fails to provide a good damping of the system oscillation when applied alone. Moreover, PSSs regulators provide good damping of system oscillations with low settling time compared to SVC controller. However, the suggested coordinated controllers remain the most efficient in providing the best damping of oscillations and reducing their settling times.

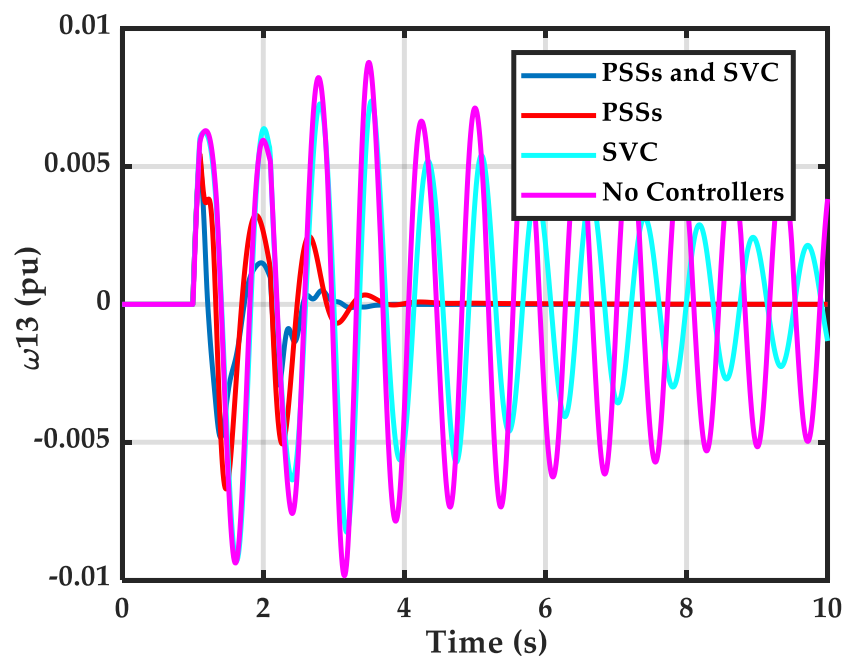

(a) Base case, under Scenario 2

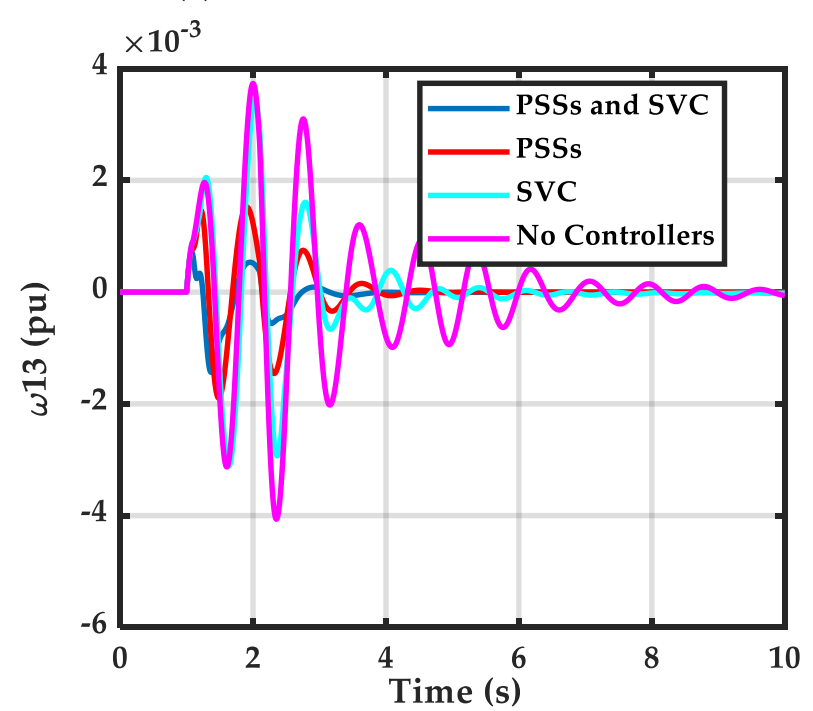

(c) Case 2, under Scenario 2

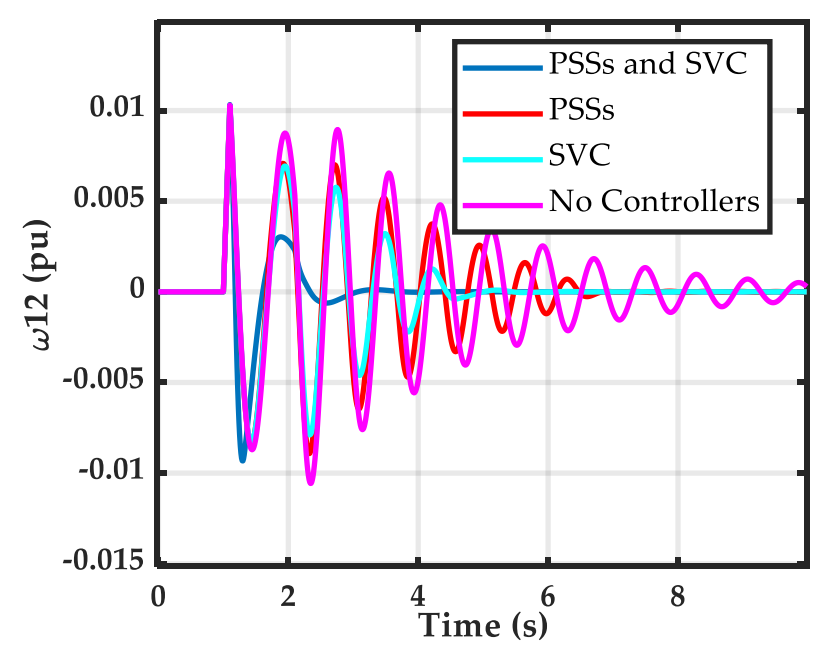

(b) Case 1, under Scenario 1

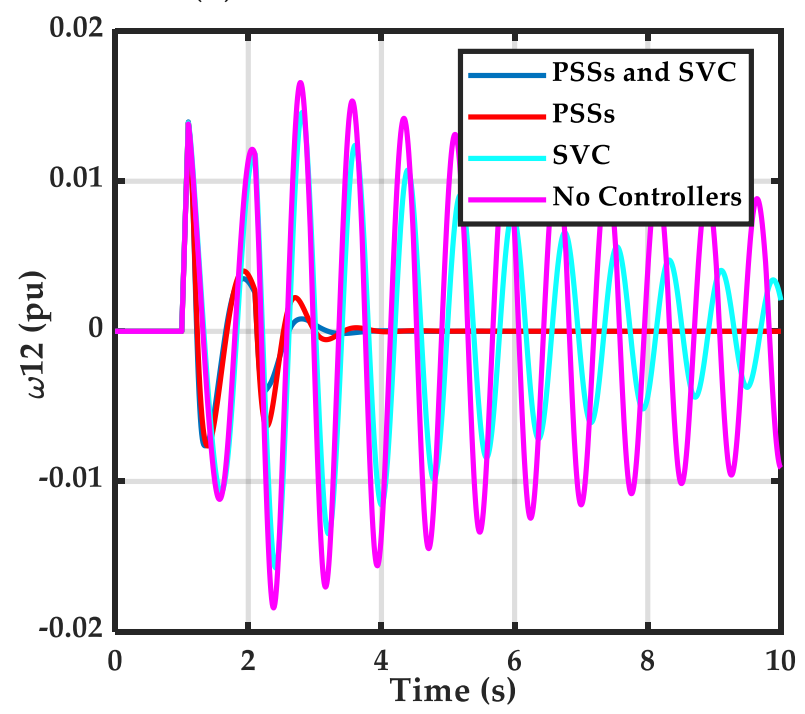

(d) Case 3, under Scenario 1

Figure 7. Variations of angular speed for various loading conditions and fault scenarios. 


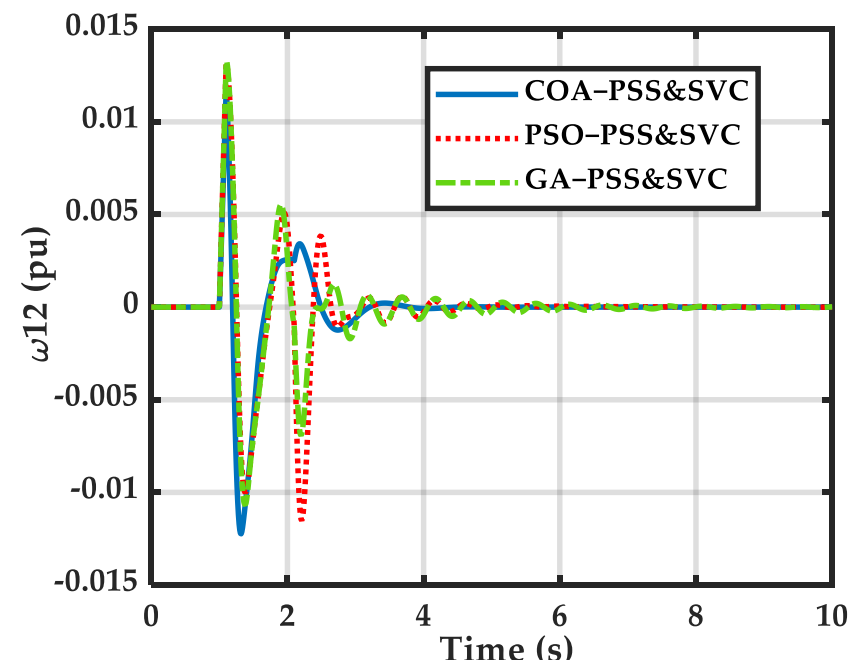

(a) Base case, under Scenario 2

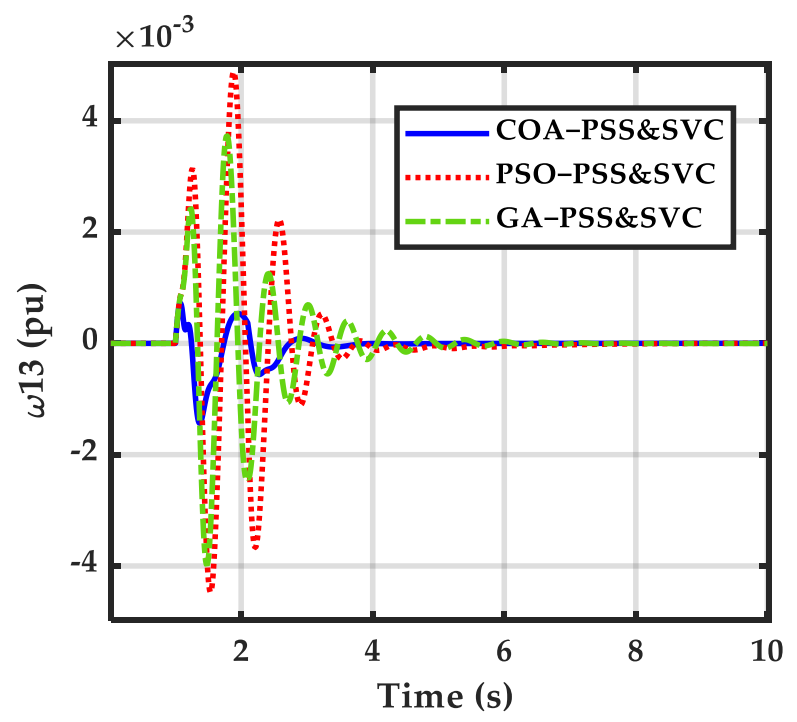

(c) Case 2, under Scenario 2

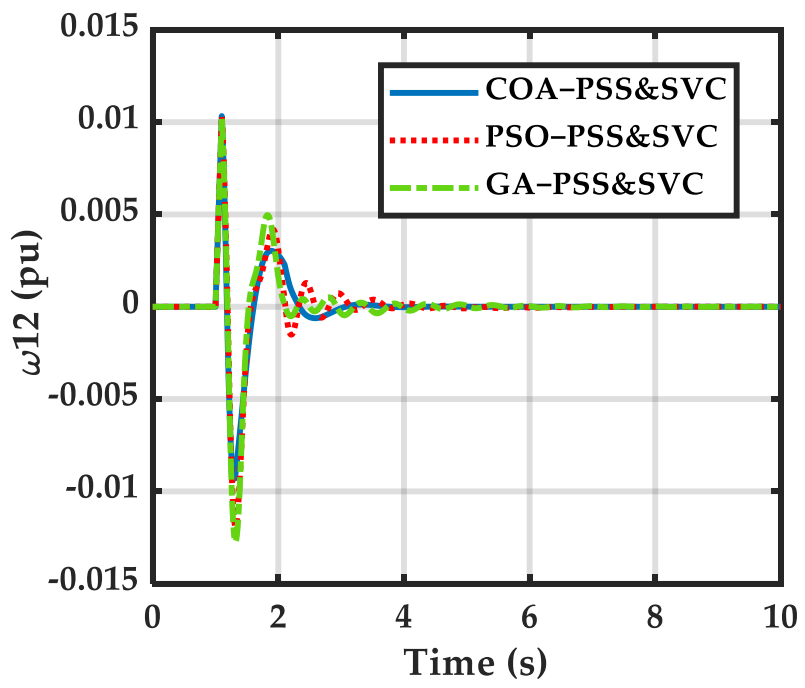

(b) Case 1, under Scenario 1

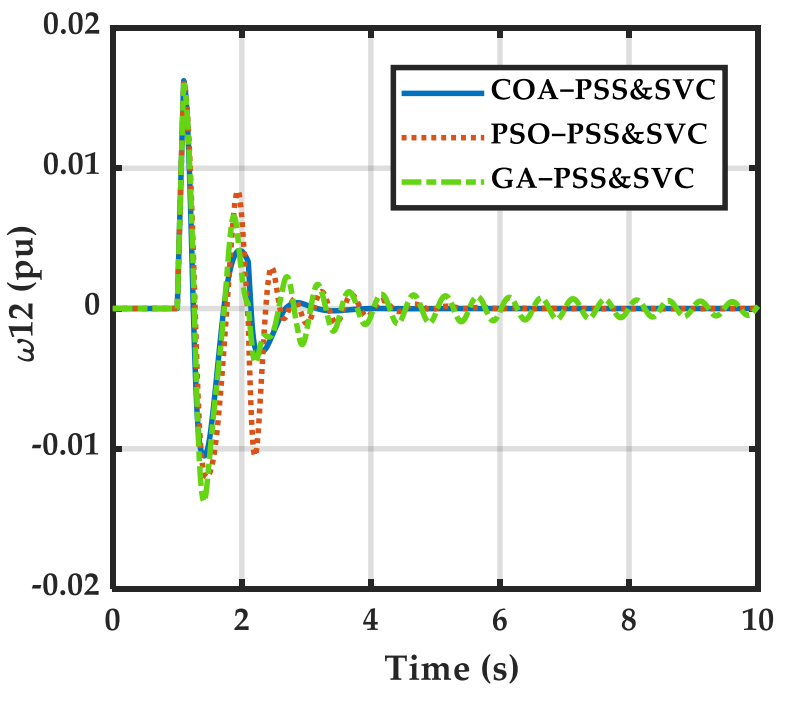

(d) Case 3, under Scenario 1

Figure 8. Variations of angular speed for various for various optimization methods.

The controllers' parameters are also tuned using GA and PSO techniques in order to assess the robustness of the suggested controllers. Table 6 shows the values of these parameters. To be more precise, the controllers' parameters are obtained for coordinated design.

Table 6. Optimal parameters of the controllers using PSO and GA.

\begin{tabular}{ccccccc}
\hline Method & \multicolumn{3}{c}{ PSO } & & \multicolumn{3}{c}{ GA } \\
\hline & PSS1 & PSS2 & SVC & PSS1 & PSS2 & SVC \\
\hline$K$ & 33.5200 & 10.4570 & 33.5264 & 21.6702 & 8.3682 & 61.0409 \\
\hline$T_{1}$ & 0.5319 & 0.4158 & 0.8352 & 1.4078 & 1.2766 & 1.2372 \\
\hline$T_{2}$ & 0.0435 & 0.9742 & 1.4676 & 1.4093 & 1.3110 & 0.4439 \\
\hline$T_{3}$ & 0.6562 & 0.0961 & 0.2832 & 0.5513 & 1.2768 & 1.3444 \\
\hline$T_{4}$ & 1.4328 & 1.2110 & 0.0379 & 0.0256 & 0.6569 & 1.1167 \\
\hline
\end{tabular}


In order to further show the robustness of the proposed controller (COA-PSS\&SVC), a comparison with GA and PSO techniques is performed in this sub-section. The parameters of the COA-PSS\&SVC controllers are those given in Table 5, whilst parameters of PSObased controllers (PSO-PSS\&SVC) and GA-based controllers (GA-PSS\&SVC) are taken from Table 6. Figure 9 shows the time responses of the speed deviations $\omega_{12}$ and $\omega_{13}$ when COA-PSS\&SVC, PSO-PSS\&SVC and GA-PSS\&SVC controllers are applied, whilst averages of settling times corresponding to responses of speed deviation $\omega_{12}$ and $\omega_{13}$ under aforementioned cases are shown in Table 7. The time responses of the variation of the SVC's susceptance $(\Delta B e)$ corresponding to the aforementioned controllers and operating conditions are given in Figures 8 and 9. From these figures and Table 7, it is obvious that the proposed controller succeeded to outperform the other controllers and to reduce the settling times of the system oscillations under severe faults and over a wide range of operating conditions. Moreover, PSO-PSS\&SVC and GA-PSS\&SVC controllers failed in providing good damping of the system oscillation in some cases like in case 3 if fault scenario 1 is applied.

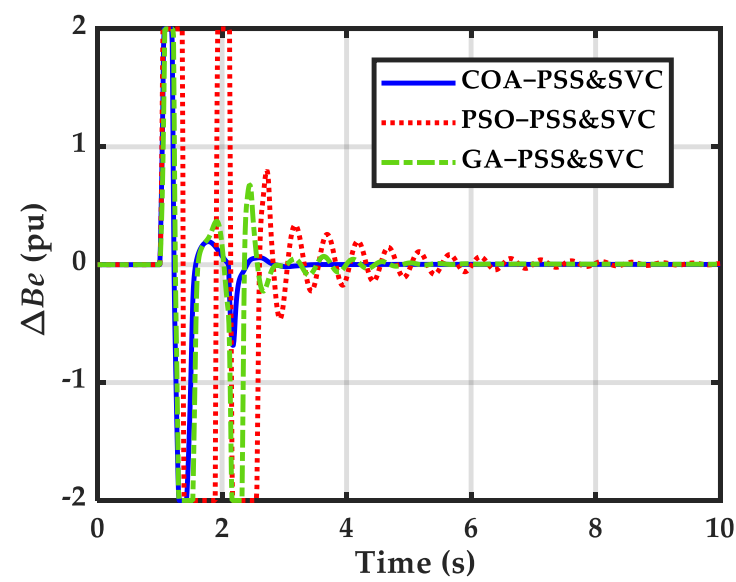

(a) Base case, under Scenario 2

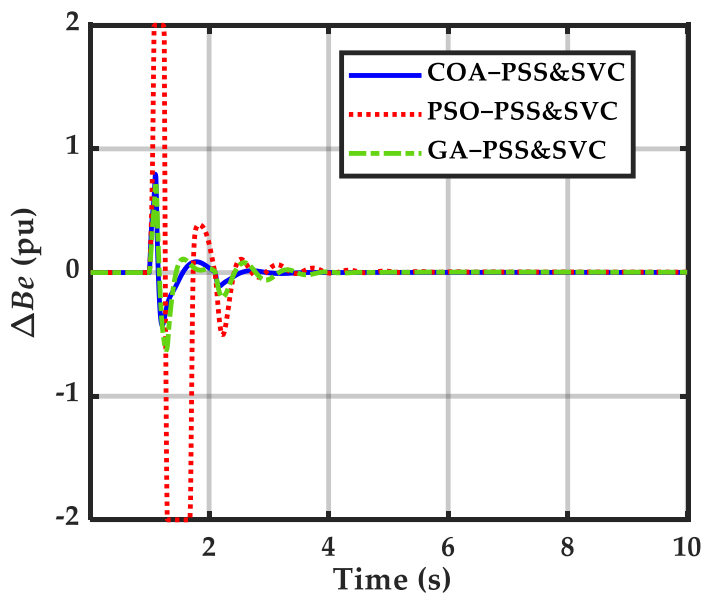

(c) Case 2, under Scenario 2

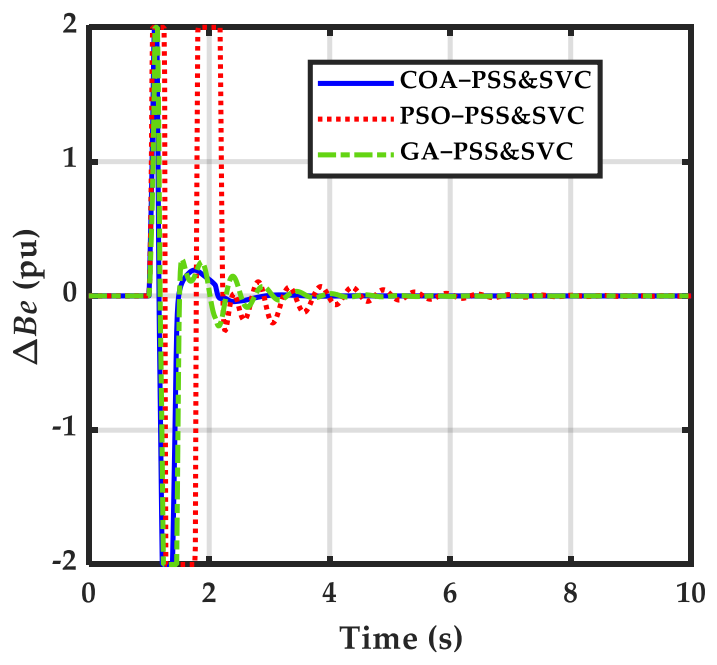

(b) Case 1, under Scenario 1

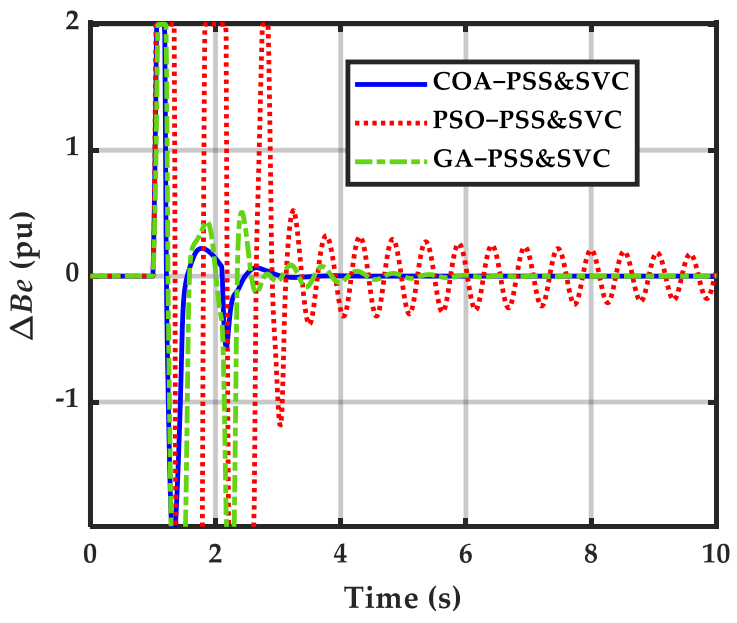

(d) Case 3, under Scenario 1

Figure 9. Variations of the SVC susceptance for various for various optimization methods. 
Table 7. Settling times in seconds.

\begin{tabular}{cccccc}
\hline & & Base Case & Case 1 & Case 2 & Case 3 \\
\hline \multirow{2}{*}{ COA-PSS\&SVC } & $\omega_{12}$ & 2.96 & 2.92 & 3.06 & 3.07 \\
\cline { 2 - 6 } & $\omega_{13}$ & 3.15 & 3.52 & 3.71 & 3.15 \\
\hline \multirow{2}{*}{ PSO-PSS\&SVC } & $\omega_{12}$ & 4.46 & 3.63 & 4.33 & 4.41 \\
\cline { 2 - 6 } & $\omega_{13}$ & 5.57 & 4.86 & 5.95 & 5.46 \\
\hline \multirow{2}{*}{ GA-PSS\&SVC } & $\omega_{12}$ & 5.87 & 4.12 & 2.67 & 9.96 \\
\cline { 2 - 6 } & $\omega_{13}$ & 9.90 & 7.18 & 5.74 & 9.99 \\
\hline
\end{tabular}

The performance and effectiveness of the proposed controller are furthermore validated using other performance index called figure of demerit (FD). As given in Equation (18), this index may depend on overshoot $(O S)$, undershoot $(U S)$ and settling time $\left(T_{S}\right)$ of the speed deviation of the machines [26]. Therefore, the best damping of system oscillation is reached for low values of FD. Table 8 shows the numerical results considering ITAE and FD indices for the COA-PSS\&SVC, NSGAII-based controller [26], SA-based PSS (SAPSS) controller [30] and FSGA-based controller [31]. Since NSGAII-based method is a multiobjective optimization technique, its best compromise solution is considered in Table 8 . From this table, it is obvious that the proposed controller corresponds to the lowest values of ITAE and FD. Therefore, it can be deduced that COA-PSS\&SVC is more efficient and more robust than the other controllers.

$$
F D=\frac{\sum_{i=1}^{N} \int_{0}^{t_{s i m}}\left(500 \times O S_{i}\right)^{2}+\left(500 \times O S_{i}\right)^{2}+T_{s i}^{2}}{N}
$$

Table 8. Performance indices.

\begin{tabular}{ccccc}
\hline & Base Case & Case 1 & Case 2 & Case 3 \\
\hline & \multicolumn{5}{c}{ ITAE } \\
\hline COA-PSS\&SVC & 6.5662 & 6.3532 & 2.5940 & 8.8123 \\
\hline NSGAII-PSS [26] & 8.690 & 10.010 & 7.542 & 14.000 \\
\hline SAPSS [30] & 11.295 & 17.996 & 19.635 & 30.998 \\
\hline FGSA [31] & 8.687 & 9.080 & 7.596 & 14.659 \\
\hline COA-PSS\&SVC & 32.7611 & 30.1703 & FD & 16.3920 \\
\hline NSGAII-PSS [26] & 33.126 & 31.706 & 28.870 & 44.1978 \\
\hline SAPSS [30] & 40.550 & 59.469 & 86.785 & 83.170 \\
\hline FGSA [31] & 38.878 & 32.139 & 33.346 & 53.492 \\
\hline
\end{tabular}

\section{Conclusions}

In this paper, a new procedure for the simultaneous coordinated design of PSSs and SVC controllers in multimachine power system is suggested. Firstly, the problem is formulated as an optimization problem where the controllers' parameters are the decision variables of the problem. The enhancement of the system stability is taken into account in the objective function in which the time responses of the speeds' deviations of machines are involved. Then, the COA algorithm is used to optimize the objective function over a wide range of operating conditions and severe fault scenarios. The performance and robustness of the proposed controller referred as COA-PSS\&SVC are assessed on a power network test, frequently used in power system stability studies. Various loading conditions comprising the base case and other extreme operating conditions are considered in the 
simulation section. Simulation results showed that the proposed coordinated design of PSSs and SVC controllers greatly improved the damping characteristics of power system oscillations, compared to the individual design. Moreover, robustness and effectiveness of the proposed controller were also compared with GA-based controller and PSO-based controller. The main outcomes show that the proposed COA-based controller seems to be an effective tool for the improvement of power system stability, in terms of ITAE, settling time and figure of demerit. Owing to its promising performance, the proposed method will be extended for hybrid power networks.

Author Contributions: Conceptualization, T.G. and B.M.A.; methodology, T.G. and A.A.; software, T.G.; validation, T.G., Y.A. and A.A.; formal analysis, T.G., Y.A. and B.M.A.; investigation, K.A. and Y.A.; writing-original draft preparation, T.G., B.M.A. and A.A.; supervision, T.G.; project administration, B.M.A.; funding acquisition, B.M.A. All authors have read and agreed to the published version of the manuscript.

Funding: This research was funded by the Deanship of the Scientific Research of the University of Ha'il, Saudi Arabia (project: RG-20059).

Institutional Review Board Statement: Not applicable.

Informed Consent Statement: Not applicable.

Data Availability Statement: Not applicable.

Conflicts of Interest: The authors declare no conflict of interest.

\section{References}

1. Marinescu, B.; Petesch, D. Three-level coordination in power system stabilization. Electr. Power Syst. Res. 2014, 111, 40-51. [CrossRef]

2. Hu, W.; Liang, J.; Jin, Y.; Wu, F. Model of Power System Stabilizer Adapting to Multi-Operating Conditions of Local Power Grid and Parameter Tuning. Sustainability 2018, 10, 2089. [CrossRef]

3. Nahak, N.; Mallick, R.K. Damping of power system oscillations by a novel DE-GWO optimized dual UPFC controller. Eng. Sci. Technol. Int. 2017, 20, 1275-1284. [CrossRef]

4. Bruno, S.; De Carne, G.; La Scala, M. Distributed FACTS for Power System Transient Stability Control. Energies 2020, 13, 2901. [CrossRef]

5. Verdejo, H.; Pino, V.; Kliemann, W.; Becker, C.; Delpiano, J. Implementation of Particle Swarm Optimization (PSO) Algorithm for Tuning of Power System Stabilizers in Multimachine Electric Power Systems. Energies 2020, 13, 2093. [CrossRef]

6. Abd-Elazim, S.M.; Ali, E.S. Bacteria Foraging Optimization Algorithm based SVC damping controller design for power system stability enhancement. Int. J. Electr. Power Energy Syst. 2012, 43, 933-940. [CrossRef]

7. Esmaili, M.R.; Hooshmand, R.A.; Parastegari, M.; Ghaebi Panah, P.; Azizkhani, S. New Coordinated Design of SVC and PSS for Multi-machine Power System Using BF-PSO Algorithm. Procedia Technol. 2013, 11, 65-74. [CrossRef]

8. Peres, W. Multi-band power oscillation damping controller for power system supported by static VAR compensator. Electr. Eng. 2019, 101, 943-967. [CrossRef]

9. Huang, W.; Sun, K. Optimization of SVC settings to improve post-fault voltage recovery and angular stability. J. Mod. Power Syst. Clean Energy 2019, 7, 491-499. [CrossRef]

10. Mitra, S.; Bhattacharya, A.; Dey, P. Small Signal Stability Analysis in Co-Ordination with PSS, TCSC, and SVC. In Proceedings of the International Conference on Computation of Power, Energy, Information and Communication (ICCPEIC), Chennai, India, 28-29 March 2018; pp. 434-441.

11. Shahgholian, G.; Movahedi, A. Power system stabiliser and flexible alternating current transmission systems controller coordinated design using adaptive velocity update relaxation particle swarm optimisation algorithm in multi-machine power system. IET Gener. Transm. Dis. 2016, 10, 1860-1868. [CrossRef]

12. Dey, P.; Mitra, S.; Bhattacharya, A.; Das, P. Comparative study of the effects of SVC and TCSC on the small signal stability of a power system with renewables. J. Renew. Sustain. Energy 2019, 11, 033305. [CrossRef]

13. Shahriar, M.S.; Shafiullah, M.; Rana, M.J. Stability enhancement of PSS-UPFC installed power system by support vector regression. Electr. Eng. 2018, 100, 1601-1612. [CrossRef]

14. Choudekar, P.; Sinha, S.K.; Siddiqui, A. Optimal location of SVC for improvement in voltage stability of a power system under normal and contingency condition. Int. J. Syst. Assur. Eng. Manag. 2017, 8, 1312-1318. [CrossRef]

15. Baadji, B.; Bentarzi, H.; Bakdi, A. Comprehensive learning bat algorithm for optimal coordinated tuning of power system stabilizers and static VAR compensator in power systems. Eng. Optim. 2020, 52, 1761-1779. [CrossRef]

16. Abdelaziz, A.Y.; Ali, E.S. Static VAR compensator damping controller design based on flower pollination algorithm for a multi-machine power system. Electr. Power Compon. Syst. 2015, 43, 1268-1277. [CrossRef] 
17. Wesley, P.; Júnior, I.C.S.; Filho, J.A.P. Gradient based hybrid metaheuristics for robust tuning of power system stabilizers. Int. J. Electr. Power Energy Syst. 2018, 95, 47-72.

18. AlRashidi, M.R.; El-Hawary, M.E. A survey of particle swarm optimization applications in electric power systems. IEEE Trans. Evol. Comput. 2009, 13, 913-918. [CrossRef]

19. Ambafi, J.G.; Adamu, S.S. Optimal siting, sizing, and parameter tuning of STATCOM and SSSC using MPSO and remote coordination of the FACTS for oscillation damping of power systems. Turk. J. Electr. Eng. Comput. Sci. 2019, 27, 4580-4595. [CrossRef]

20. Shukla, R.; Singh, D. Selection of parameters for advanced machining processes using firefly algorithm. Eng. Sci. Technol. Int. J. 2017, 20, 212-221. [CrossRef]

21. Gurung, S.; Naetiladdanon, S.; Sangswang, A. coordination of power-system stabilizers and battery energy-storage system controllers to improve probabilistic small-signal stability considering integration of renewable-energy resources. Appl. Sci. 2019, 9, 1109. [CrossRef]

22. Devarapalli, R.; Bhattacharyya, B. Optimal controller parameter tuning of PSS using sine-cosine algorithm. Metaheuristic and Evolutionary Computation: Algorithms and Applications. In Studies in Computational Intelligence; Springer: Singapore, 2021; Volume 916, pp. 337-360.

23. Pierezan, J.; Dos Santos Coelho, L. Coyote Optimization Algorithm: A New Metaheuristic for Global Optimization Problems. In Proceedings of the 2018 IEEE Congress on Evolutionary Computation (CEC), Rio de Janeiro, Brazil, 29 January 2018; pp. 1-8.

24. Abd-Elazim, S.M.; Ali, E.S. Coordinated design of PSSs and SVC via bacteria foraging optimization algorithm in a multimachine power system. Int. J. Electr. Power 2010, 41, 44-53. [CrossRef]

25. Farah, A.; Guesmi, T.; Hadj Abdallah, H.; Ouali, A. A novel chaotic teaching-learning-based optimization algorithm for multi-machine power system stabilizers design problem. Int. J. Electr. Power Energy Syst. 2016, 77, 197-209. [CrossRef]

26. Guesmi, T.; Farah, A.; Abdallah, H.H.; Ouali, A. Robust design of multimachine power system stabilizers based on improved non-dominated sorting genetic algorithms. Electr. Eng. 2018, 100, 1351-1363. [CrossRef]

27. Conner, M.M.; Ebinger, M.R.; Knowlton, F.F. Evaluating coyote management strategies using a spatially explicit, individual-based, socially structured population model. Ecol. Model. 2008, 219, 234-247. [CrossRef]

28. Arfaoui, J.; Hegazy, R.; Al-Dhaifallah, M.; Ibrahim, M.N.; Mami, A. Simulation-Based Coyote Optimization Algorithm to Determine Gains of PI Controller for Enhancing the Performance of Solar PV Water-Pumping System. Energies 2020, 13, 4473. [CrossRef]

29. Pai, M.A.; Sen Gupta, D.P.; Padiyar, K.R. Small Signal Analysis of Power Systems; Narosa Publishing: New Delhi, India, 2004.

30. Abido, M.A. Robust design of multimachine power system stabilizers using simulated annealing. IEEE Trans. Energy Convers. 2000, 15, 297-304. [CrossRef]

31. Ghasemi, A.; Shayeghi, H.; Alkhatib, H. Robust design of multimachine power system stabilizers using fuzzy gravitational search algorithm. Int. J. Electr. Power Energy Syst. 2013, 51, 190-200. [CrossRef] 